\title{
Use of 3D Printing TeChNology In TEACHING THE BASICS OF MiLling TECHNOLOGY
}

\author{
Lubos Kroft, Katerina Bicova \& Aneta Milsimerova
}
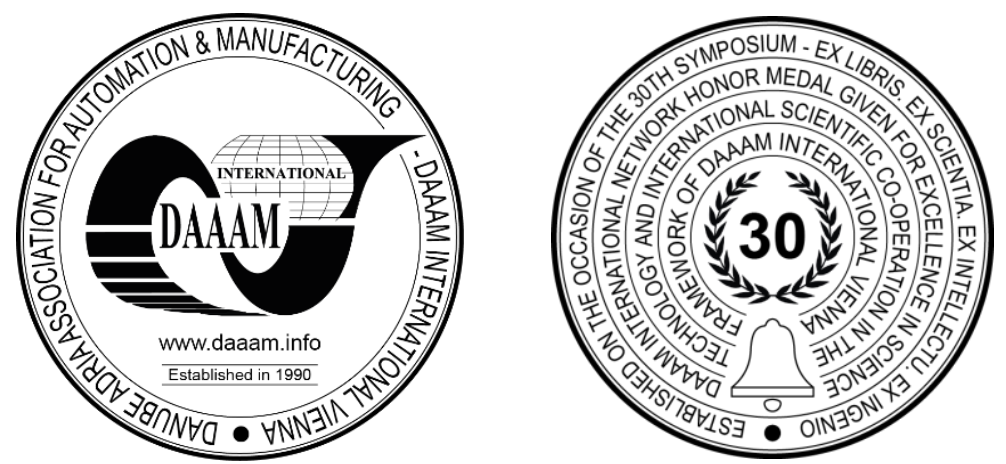

This Publication has to be referred as: Kroft, L[ubos]; Bicova, K[aterina] \& Milsimerova, A[neta] (2020). Use of 3D Printing Technology in Teaching the Basics of Milling Technology, Proceedings of the 31st DAAAM International Symposium, pp.0323-0327, B. Katalinic (Ed.), Published by DAAAM International, ISBN 978-3-902734-29-7, ISSN 1726-9679, Vienna, Austria

DOI: $10.2507 / 31$ st.daaam.proceedings.045

\begin{abstract}
This paper deals with current possibilities of the utilization of the 3D printing technologies in the area of schooling and education. The main idea is to use current rapid development of the technique and technology of creating 3D models to improve better interaction with students, especially in the teaching of the milling machining basics. The aim is to optimize the teaching so the subject matter is widely comprehensible to attendees and to deepen the interaction between an academic and students. As a result, the presentation of the topic becomes more interesting and easier to be understandable for every student.
\end{abstract}

Keywords: Milling; theory of machining; 3D print; prototyping; innovation of the teaching.

\section{Introduction}

3D printing technology belongs currently amongst top technologies and it expands into wide ranges of areas. It applies for example into education, households, mechanical engineering as well as food industry or health care. It can be said that the most widespread form of 3D printing technology is the use of plastic and printing of plastic components. In addition to the 3D print there are other innovative methods, tools and procedures, which are possible and in a current time necessary to involve them when some problems are solved, prototype parts are designed, projects are solved, etc. From the view of students, for example the design of montage system connected to virtual and physical reality seems to be interesting, so the extension of teaching by practical experiments [2].

This paper is focused on 3D print from the view of the integration of innovative method to support the interaction between academic and students. In Czech Republic, the support of 3D print in education, it is not widespread as far as in abroad. However, within the solution of European projects according to individual calls, the implementation can be realized [3]. Study programs are mainly focused on acquainting students with modern possibilities of prototyping with basic principles of 3D print and its use in the industrial field. This new unexplored area opens new possibilities of pedagogic research, mainly in the area of technical creativity. Students thesis get at another level, they are enriched with real design model, etc., which increases the interest of students and concurrently supports their ingenuity [4, 5, 6]. The research of YSoftCorporation, a.s. company also comes to the same conclusions based on their research focused on the usage of 3D print in the teaching [7]. 


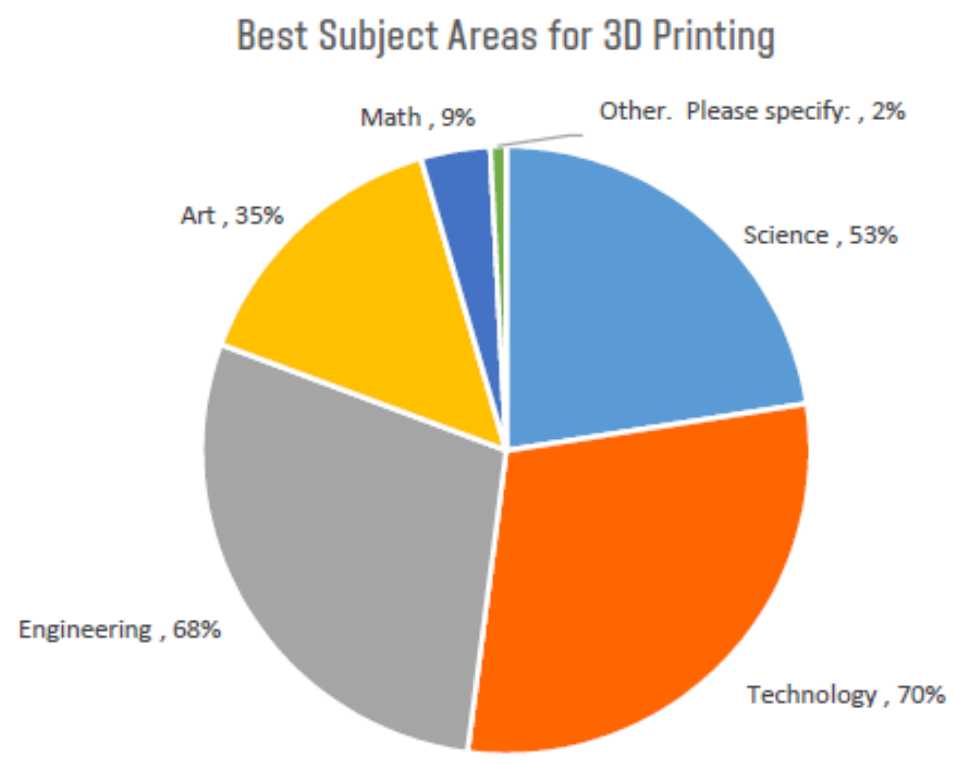

Other:

Education, Medical, Medicine, Design, Prototyping

Fig. 1. Graph of the best subject Areas for 3D Printing

How about to use 3D print to facilitate the imagination and visualization in more complex areas of a current topic. There are many of educational aids, but when targeting on basics of milling machining technology, it is a specific area in this case. Even if there are many of scientific publications, verbal explanation of targeted problematic is insufficient for some students. So the task was following: How to demonstrate basics of milling machining without real cutting tools and machine tools?

\section{Current State}

The basic teaching of machining technology contains basics of common used and special types of machining. The main aim is to get to know with machining which belongs to the most widespread production technologies in mechanical engineering. Machining produces components from the input stock to the final product. The principle of the machining process is to remove the chip from the stock with the cutting tool until the final shape of the part with precise dimensions is created. Drilling is determined for machining holes, turning is determined for machining of rotating parts, milling machining is determined for machining of the planar surfaces, grinding is determined for creating precise surfaces, etc.
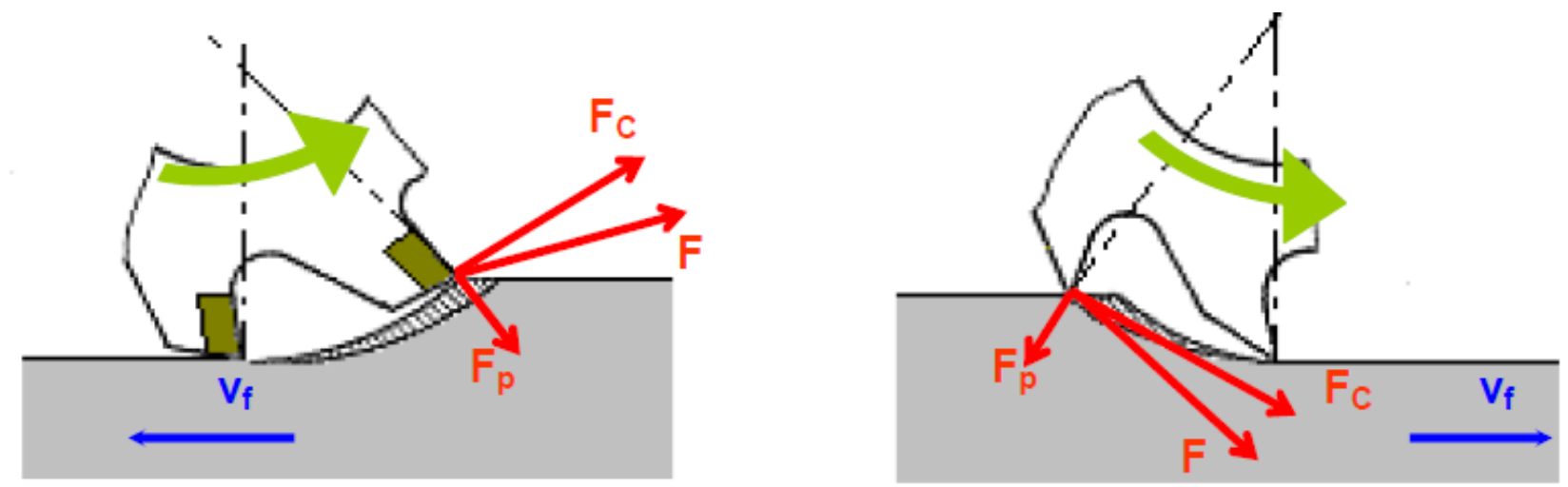

Fig. 2. Consecutive and inconsistent milling [8]

Milling machining belongs among one of the first technologies which is subject matter of the teaching. It is about chip machining of inner and outer faces, where the main rotational motion and feedrate are done by the cutting tool. These are a basic principle a student knows. The classification of milling cutters and milling strategies is usually an obstacle for students when covering this topic. As the same as basic principles of movements or differentiation between conventional and non-conventional milling (See on Fig. 2). 
Safety is another disadvantage when demonstration the real cutting tools on the workplace. Real cutting tools are sharp and injury could happen when manipulating with them unprofessionally. Also, their size adds to it. It would be necessary to get the tool with increased dimensions to show clearly all cutting edges, faces, angles and other properties of the tool. But due to the higher weight it would be more complicated to manipulate with these tools. There are illustrations of practical use of milling tools on different kinds of surfaces in the following picture (Fig. 3).

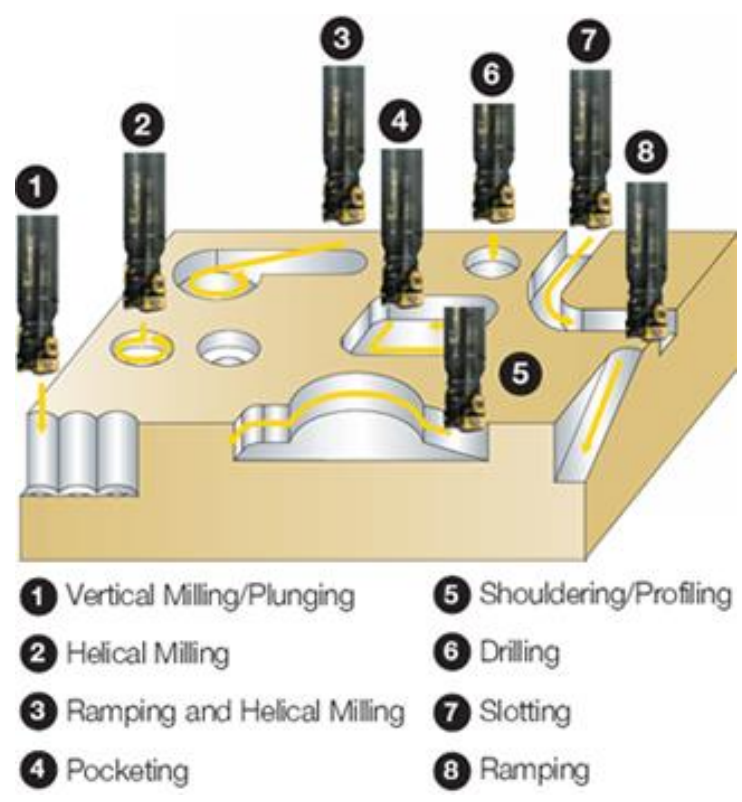

Fig. 3. Milling of various surface shapes [8]

\section{Use of 3D print when innovating the teaching}

Based on above mentioned disadvantages and needs our team has come to the idea to use 3D print technology to support the teaching. The Department of Machining Technology has a 3D printer Original Prusa I3 MK3. Prusa I3 MK3 is offering the same $250 \times 210 \times 200 \mathrm{~mm}$ build volume, a sturdy frame with iconic orange-colored 3D prints parts, as well as staple features like the removable magnetic print bed and power recovery. [9] The programs for creating a model are exported from "Slic3r" software. It is a simple printer using a PLA plastic. For a print sample, see fig. 4.

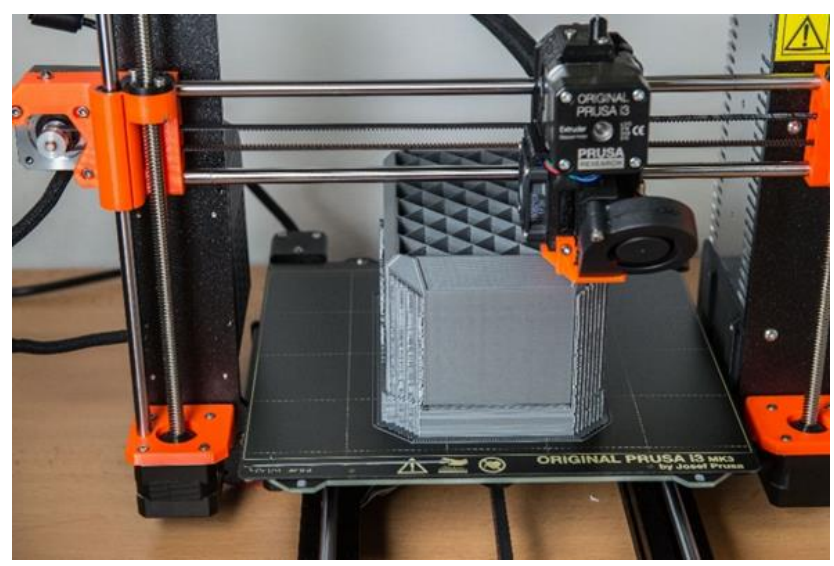

Fig. 4. The 3D printer

The following pictures (5-7) demonstrate printed tools and jigs which are now used for teaching of basic principles of milling technology. The 3D models are modified according to the specific need of the current subject matter. Most of the models are taken from the manufacturers of cutting tools and then modified according to the current needs. 3D printed models of cutting tools are safe, lightweight and visual so they correspond to all required parameters. It is possible to safely manipulate with enlarged cutting tools due to their lightweight. The benefit is that is possible to easily operate whit these models and apply them to the selected surface when explaining the application of corresponding type of milling cutter. When compared to the description of the principle from the picture, this benefit is incomparable (See pic. 6). A student can these movements of cutting tools try out on his own and get a first-hand experience which helps to better understand and remember this principle. 


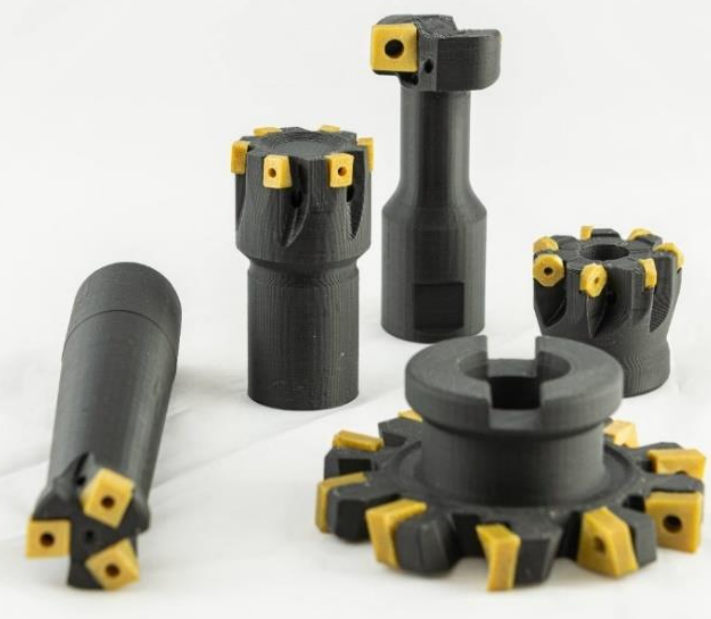

Fig. 5. 3D printed models of milling cutters - different kinds of cutting tools

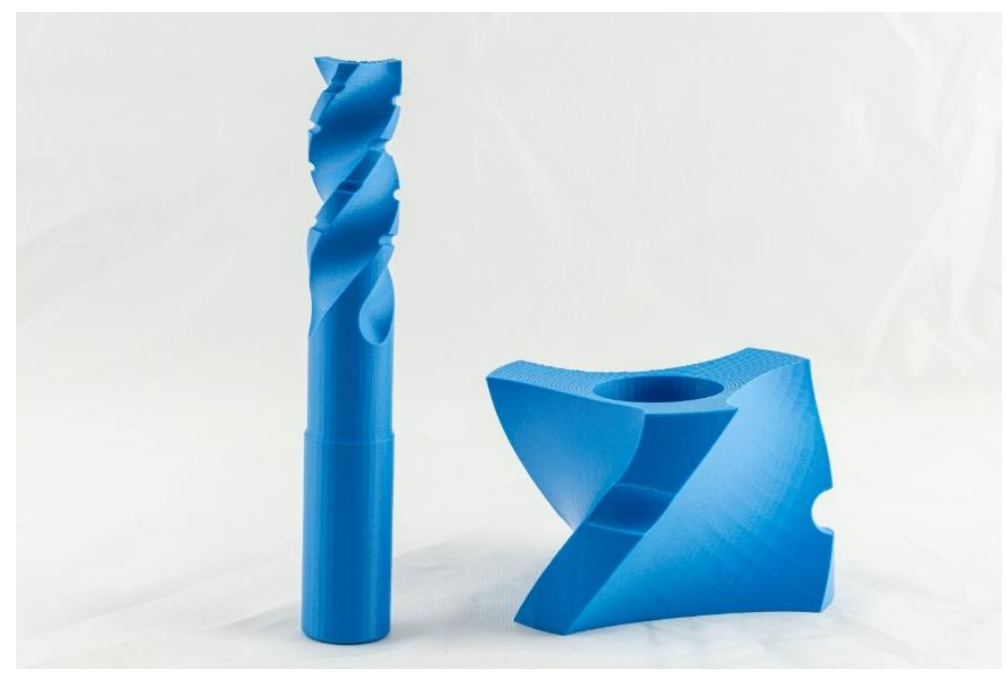

Fig. 6. Detail of a milling cutter and chip breaker

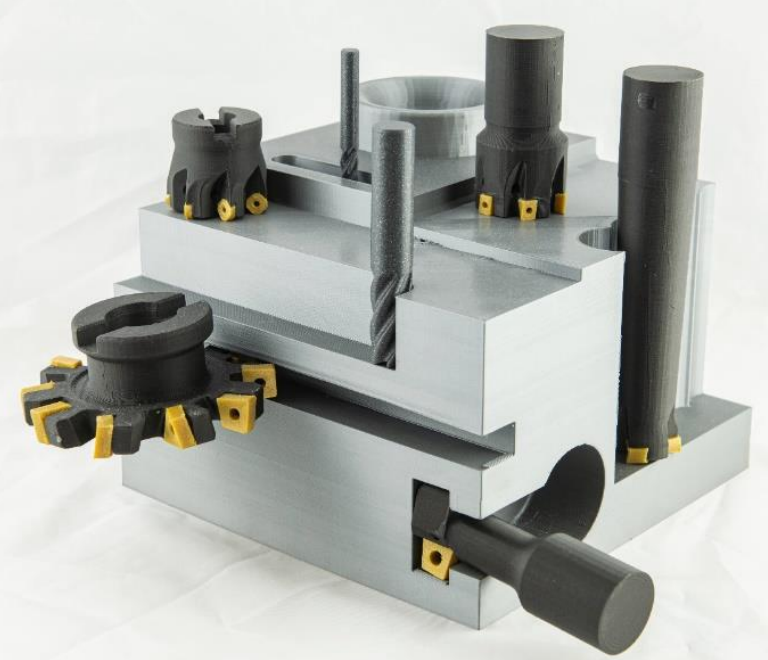

Fig. 7. Application of selected milling cutters on specific surfaces 


\section{Conclusion}

Educational institutions are attempting to quickly respond to new modern trends and are preparing or are already realizing implementation of these technologies into the teaching. This new, uncovered area opens new possibilities of pedagogic research, mainly in the area of technical creativity.

We used these facts as a motivation because teaching in our modern era requires closer interaction between the teacher and the student. We have harnessed force of this modern technology even if we haven't realized the teaching on 3D printers. Our idea was about usage of modern technologies when teaching years known principles. Thanks to this improvement, the real idea of students about the given issue has increased. We are now trying to apply this idea in other subjects. Verification of effectiveness and confirmation of increased efficiency in receiving the issue was recorded with higher success rate in following written exam tests when compared to previous years. The feedback from students is also very positive. We are able to better pass on knowledge and make engineering technologies easier to understand thanks to this innovation of current teaching.

\section{Acknowledgments}

This article was created under the project SGS-2019-008: Research and Development for Innovation in the Field of Manufacturing Technology - Machining Technology III.

\section{References}

[1] Malega, P., Kovac, J. (2016). Design of assembly system-mixed reality modelling, Proceedings of the International DAAAM Symposium. Volume 27, Issue 1, Pages 289-297. Mostar. Available from: https://www.scopus.com/record/display.uri?eid=2-s2.0-85010824811\&origin=resultslist\&sort=plf-

$\mathrm{f} \& \mathrm{src}=\mathrm{s} \& \mathrm{nlo}=\& \mathrm{nl} \mathrm{r}=\& \mathrm{nls}=\& \mathrm{sid}=\mathrm{a} 2 \mathrm{da} 00872 \mathrm{a} 58 \mathrm{aa} 76 \mathrm{edea} 0 \mathrm{ae} 2 \mathrm{e} 441 \mathrm{bfc} 5 \& \mathrm{sot}=\mathrm{a} \& \mathrm{sdt}=\mathrm{a} \& \mathrm{sl}=27 \& \mathrm{~s}=\% 28 \mathrm{CONF} \% 28 \mathrm{~d}$ aam\%29\%29+AND+\%28milling\%29\&relpos=55\&citeCnt=0\&searchTerm $=$

[2] Kaufnerová, A., Kutlwašer, J.(2019). The course „Practice of experimental methods in machining“, Proceedings of the International DAAAM Symposium. Volume 30, Issue 1, Pages 989-994. Zadar. Available from: https://www.scopus.com/record/display.uri?eid=2-s2.0-85077853547\&origin=resultslist\&sort=plf-

$\mathrm{f} \& \mathrm{src}=\mathrm{s} \& \mathrm{sid}=42 \mathrm{f} 2 \mathrm{~d} 7756070 \mathrm{~d} 8993 \mathrm{e} 8389248 \mathrm{a} 95 \mathrm{ab} 11 \& \mathrm{sot}=\mathrm{a} \& \mathrm{sdt}=\mathrm{a} \& \mathrm{sl}=28 \& \mathrm{~s}=\% 28 \mathrm{CONF} \% 28 \mathrm{daaam} \% 29 \% 29+\mathrm{A}$ ND+\%28teaching\%29\&relpos $=3 \&$ citeCnt=0\&searchTerm $=$

[3] Krotký, Jan. (2014). 3D tisk v prŕpravě budoucích učitelů, Trends in education, Available from: https://www.researchgate.net/publication/309427437_3D printing in preparation for future teachers

[4] 3D Printers for Schools (2019). Universities \& Education. Available from: https://www.lpfrg.com/en/professionals/education/

[5] Hrabovsky, J. (2016) Jak vhodně integrovat 3D tisk do výuky. MM Spektrum. Available from: https://www.mmspektrum.com/clanek/jak-vhodne-integrovat-3d-tisk-do-vyuky.html

[6] 3D Printers in Schools: Uses in the Curriculum (2014) Enriching the Teaching of STEM and Design Subjects. In: Department for Education websites [online]. London, Available from: https://www.gov.uk/government/uploads/system/uploads/attachment_data/file/251439/3D_printers_in_schools.pdf

[7] YSoftCorporation,a.s (2017). 3D PRINTING IN EDUCATION - 2016 REPORT CARD. Available from https://www.ysoft.com/CMSPages/GetFile.aspx?guid=039168de-d99b-4f99-9285-dce84d37c42b

[8] Milling of various surface shapes (2014) Retrieved from: https://www.fgmtooling.com/kennametal/milling-toolingtool/indexable-milling-face-copy-shoulder-mill/shoulder-mills/shoulder-mill-inserts/multifunctional-cutterinserts.html

[9] Průša (2019) Website - Prusa 3D print, Retrieved from https://www.prusa3d.cz/ 